Article

\title{
Impact of Economic Growth, Environmental Pollution, and Energy Consumption on Health Expenditure and R\&D Expenditure of ASEAN Countries
}

\author{
Muhammad Haseeb ${ }^{1}{ }^{(0)}$, Sebastian Kot ${ }^{2,3, *(\mathbb{D})}$, Hafezali Iqbal Hussain ${ }^{1}$ and \\ Kittisak Jermsittiparsert ${ }^{4}$ (i) \\ 1 Taylor's Business School, Taylor's University Lakeside Campus, 1 Jalan Taylors, Subang Jaya 47500, \\ Malaysia; muhammad.haseeb@taylors.edu.my (M.H.); hafezali.iqbalhussain@taylors.edu.my (H.I.H.) \\ 2 Faculty of Economic and Management Sciences, North-West University, Vaal Triangle Campus, \\ P.O. Box 1174, Vanderbijlpark 1900, South Africa \\ 3 The Management Faculty, Czestochowa University of Technology, 42.201 Czestochowa, Poland \\ 4 Social Research Institute, Chulalongkorn University, Bangkok 10330, Thailand; kittisak.j@chula.ac.th \\ * Correspondence: sebacat@zim.pcz.czest.pl; Tel.: +48-34-3250-345
}

Received: 30 July 2019; Accepted: 16 September 2019; Published: 20 September 2019

check for updates

\begin{abstract}
The purpose of the current study was to examine the determinants of R\&D expenditure and health expenditure of ASEAN countries. The research objectives were developed to analyze the short-term as well as the long-term impact of economic growth, environmental pollution, and energy consumption on health and R\&D expenditures. The data was collected for ten years for ASEAN countries using the Auto-Regressive Distributed Lag (ARDL) approach, which helped the researcher to assess long-run as well as the short-run association of these variables. The findings revealed that environmental pollution, energy consumption, and economic growth had a significant positive impact on health expenditure as well as on R\&D expenditure of ASEAN countries in long-run. The findings further revealed that environmental pollution and economic growth had a significant impact on R\&D expenditure in short-run; however, there was no significant impact of energy consumption on R\&D expenditure in short-run. It was also found that there was no significant impact of any of the independent variables, i.e., energy consumption, economic growth, and environmental pollution, on health expenditure in short-run. The current study and findings have significant implications in theory and practice.
\end{abstract}

Keywords: environmental pollution; economic growth; energy consumption; health expenditure; R\&D expenditure; ASEAN countries; ARDL approach

\section{Introduction}

The critical debate has started on the correlation between health expenditure, environmental condition, and economic growth relationship with the increase in countries' concerns related to health and pollution. In this regard, previous studies suggest a strong association between health expenditure, energy, R\&D, environmental pollution, and GDP of a country. The association of environment with a country's economy has been discussed by several researchers since 1960s; however, the relationship of the environment with health and R\&D conditions has been scarcely considered by past researchers in such type of models [1-3]. The increasing rate of globalization has given rise to certain concerns of countries related to environmental pollution, social protection, and health conditions [4]. The pressure from globalization has further increased the concerns of Association of Southeast Asian Nations 
(ASEAN) countries because they are already going through the pressure of "population aging". The increasing rate of globalization, urbanization, industrialization, and energy consumptions in ASEAN region has further led these countries to focus on their health and R\&D conditions that are being largely influenced due to environmental pollution and energy consumption [5-7].

Many past studies have focused on different determinants of government spending in different domains [8-11]. There are several predictors of overall government spending and particular welfare spending of countries, among which the economic and environmental determinants have gained larger importance due to their potential to influence these expenditures $[4,12]$. Among welfare expenditure, the health expenditure is the most important expenditure made by the government [13]; however, most of the portion of existing literature about the determinants of health and welfare expenditure has focused on Organization of Economic Cooperation and Development (OECD) countries and other regions, while there is a lack of particular focus on ASEAN countries. Therefore, the current study aimed to examine the relationship between economic growth, environmental pollution, energy consumption, $R \& D$ expenditure, and health expenditure in the particular context of ASEAN countries. The significant contribution and the relevance relationship of the studied variables are highlighted in many earlier studies [14-16]. Moreover, to measure a country's health expenditures, the aggregate expenses of public and private health expenditures were utilized for all ASEAN economies. Similarly, $R \& D$ expenditure was measured from summing up the R\&D budgeted spending of the ASEAN countries. As for the explanatory variables, three crucial factors of energy consumption, economic growth, and environmental pollution were adopted. Environmental pollution was measured using carbon dioxide emanations. Moreover, energy use per capita was calculated as a proxy to measure energy consumption. Finally, to measure a country's economic development, the measure of gross domestic growth was utilized in the current investigation.

Past scholars have endorsed the view that while environmental pollution due to $\mathrm{CO}_{2}$ emissions has been responsible for incurring heavy health expenditure, Nitrous oxide emissions and other toxic emissions have harmed the health conditions of a country and spread different infectious diseases. Therefore, several studies are carried out on the relationship between environment and health worldwide in a new way. The attempt is to efficiently explain the phenomenon through which environmental pollution can affect the health expenditure of a country [6,17]. Previous studies have also emphasized that climate change has the potential to influence the functioning of several ecosystems affecting human health. Although it can be beneficial in some cases, most past researchers suggest that climate change has an overall harmful impact on health; the major driver being air pollution [18-20]. ASEAN region is one of those regions that are considered to be most influenced by climate change because $\mathrm{CO}_{2}$ emissions and energy consumptions in ASEAN countries are increasing environmental pollution [21].

To ensure health economies, the endeavors of governments and policymakers are confined to identify solutions to maintain environmental quality for which, environmental degradation is a severe threat [22]. The role of greenhouse gases is considered vital to create environmental pollution, which subsequently can lead to air pollution that exerts several adverse effects on human health. Toxic greenhouse emanations cause greater concentrations of pollutants in the atmosphere. The substantial portion in greenhouse gases is attributed to carbon dioxide $\left(\mathrm{CO}_{2}\right)$ that accounts for $76 \%$ of greenhouse gases. Scientific evidence has highlighted that $\mathrm{CO}_{2}$ can stay trapped in the earth atmosphere for a very long time, creating concentration that can last much longer than other greenhouses gases; therefore, could hold the long-lasting impact of environmental pollution. In a similar context, the empirical link between $\mathrm{CO}_{2}$ and health expenditure is based on the massive contribution of $\mathrm{CO}_{2}$ in greenhouse gas emission that underlies the potential to disrupt environmental stability, leading to drastic climate change and ozone depletion. Thus, the increase in $\mathrm{CO}_{2}$ emanations results into several natural calamities and associated diseases, thereby carrying disastrous effects on human health in the form of extreme climate events, such as rising frequency of heat-waves that are often lethal and also expands the series of disease-carrying creatures, such as mosquitoes and ticks. In compliance with the critical 
relationship between the variables, many studies analyzed the empirical link between $\mathrm{CO}_{2}$ emission and human health $[1,2,14]$. Moreover, Qureshi et al. [23] also stated that contact with air pollution, among other ecological pressures, create high morbidity, disability, and mortality. The study analyzed the role of energy consumption and $\mathrm{CO}_{2}$ emission in affecting several health services in Malaysia. More recently, Wang et al. [22] stated that to identify how healthy any country's inhabitants are, the values of health expenditures represent a good measure. Following that, the study examined the impact of health expenditure on $\mathrm{CO}_{2}$ emission in Pakistan. Likewise, in a panel investigation of 51 countries, Chaabouni and Saidi [1] also investigated the causal connection between $\mathrm{CO}_{2}$ emission, health expenditures, and economic growth. Acknowledging the significance of research and development in modern economies, Koçak and Ulucak [24] stressed on analyzing the association between energy R\&D expenditures and $\mathrm{CO}_{2}$ emissions in OECD countries. Likewise, Kahouli [15] also emphasized on the empirical link between $\mathrm{R} \& \mathrm{D}$ expenditures, $\mathrm{CO}_{2}$ emanations, energy consumption, and economic growth in Mediterranean nations. Hence, the above discussion makes it critically imperative to improve our understanding regarding the role of $\mathrm{CO}_{2}$ emanations, energy consumption, and economic growth in instigating health and research and development expenditures in the selected ASEAN region.

Air pollution, water contamination, industrialization, and urbanization are some key drivers of climate change. There are a number of existing studies discussing the determinants of climate change, e.g., $[19,20,25,26]$; however, none of them focused on the impact of environmental pollution on health and R\&D expenditure. The current study, therefore, attempted to suggest that increasing environmental pollution has raised several health concerns due to which large governmental expenditure has been allocated to the R\&D and health departments. The objective is to control environmental pollution and health issues through research and improving health conditions. Therefore, the first objective of the current study was to assess the impact of environmental pollution on R\&D and health expenditures in ASEAN countries.

The second part of the current model focused on the great role of energy consumption in determining the R\&D as well as health expenditure because the increasing urbanization and industrialization have raised a number of health and environmental issues associated with energy consumptions. There is a great need to mobilize the R\&D and health sectors and to make proper efforts to control the negative outcomes of this urbanization and industrialization [21]. The increasing energy consumption in ASEAN countries is also raising severe health and pollution issues that need to be controlled from which R\&D intervention is required. The second objective of the current study, therefore, was to examine the impact of energy consumption on $R \& D$ and health expenditures in ASEAN countries.

The third key part of the current model was about the role of economic growth in determining the health and R\&D expenditures of a country. It is suggested that the increasing GDP of a country potentially contributes in the enhancement of its national health and R\&D expenditures because increasing economic growth is followed by prosperity and development of the nation, ultimately enhancing its national health and environmental conditions [11,27]. The third objective of the current paper was, therefore, to analyze the impact of economic growth on $R \& D$ and health expenditures in ASEAN countries.

The focus of all three objectives of the current study was on the ASEAN region. This study attempted to fill the gap caused by the limited focus of past studies on this region regarding environmental, economic, and energy-related determinants and their impact on health and R\&D expenditures. The current study prepared a model combining environmental, economic, and energy-related determinants in a single study. This model would analyze the impact of these determinants on health and R\&D expenditures in ASEAN region perspective.

The remaining portion of the current paper has been designed in five sections. In the second section, the literature about current variables and their relationships has been presented and reviewed. In the third section, the methodology and econometric modeling approach used in the current study 
have been elaborated. Section 4 provides the analysis and results followed by the discussion of results. The last section presents the conclusion of the overall study.

\section{Literature Review}

"Health Capital" is an important part of human capital, and thus expenditure on health has gained large importance in the critical domain on public expenditure and public policy. The expenditure on health may vary in different countries with respect to economic conditions, environmental concerns, and other contextual factors, but it is that portion of total public expenditure of a country that is spent on health facilitation in a country [12]. Similarly, the expenditure on R\&D is significant in a country's development because this expenditure contributes towards the enhancement of a country's economy, health, education, agriculture, environment, and other domains. R\&D as the main source of the growth in a country was argued by Damijan et. al. [10], who researched on eight transition countries and suggested that $R \& D$, has a potential to transfer technology in developing countries. However, this research only focused on the consequences of $R \& D$ and did not discuss particular determinants of $R \& D$ expenditure in a country or factors which $R \& D$ expenditure is derived from.

Economic growth is defined as an increase in the overall output of goods and services in a country. A country is said to be growing economically when the inflation-adjusted market value of goods and services produced in that country increases. The main indicator of economic growth is GDP, the increase in which depicts the growth of country's economy. Figure 1 illustrates that the economic growth of most ASEAN countries has increased in the past five years, meaning favorable trends seen in their GDP [28].

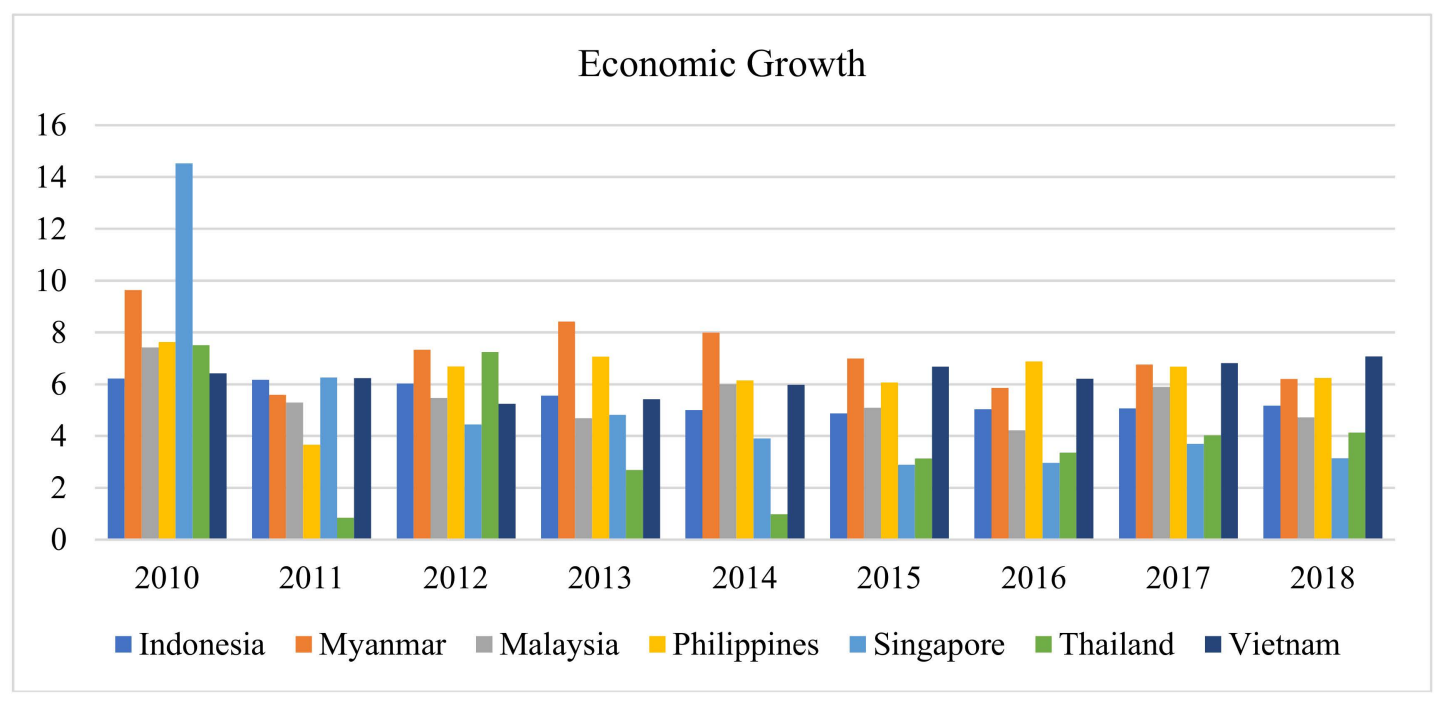

Figure 1. Top ASEAN countries' economic growth.

The increased economic growth has led these countries to considerably contribute to the health and R\&D sectors to improve health and environmental conditions in the region. Hence, there is a need to examine whether the economic growth of ASEAN countries has significantly contributed to their health and R\&D expenditures.

Another important predictor of health and R\&D expenditures is environmental pollution, which can be defined as infection and pollution in the biological as well as physical components of an ecosystem. Environmental pollution in a country is associated with the contamination of components of its ecosystem due to which normal environmental process in the country gets influenced adversely [29]. Among several determinants of environmental pollution, the economic determinants have gained good attention in past literature. For example, Lan et al. [30] suggested two important predictors of environmental pollution in China, i.e., Foreign Direct Investment (FDI) and human capital. According to them, FDI has a significant impact on environmental pollution of China; however, this impact is 
much dependent on the level of human capital. Lan et al. [30], in another study, argued that economic factors could play a major role in increasing a country's environmental pollution but did not discuss consequences or the potential of environmental pollution influencing governmental expenditure on health and R\&D.

Another factor, which has great potential to affect a country's expenditure on health and R\&D, is the level of energy consumption. Energy consumption can be defined as the amount of power or energy used in a country. The energy consumption in ASEAN countries has increased significantly and intermittently in the past few years, raising the need to increase expenditure on health as well as $R \& D$ to cope with the environmental and health issues. Evidence reveals that this increase in energy consumption in ASEAN countries has mobilized R\&D to focus on maintenance, enhancement, and protection of energy sources. Saboori and Sulaiman [31] argued that there is a close association between energy consumption, environmental pollution, and economic growth. Heidari et al. [32] also accepted this relationship based on their study in five major ASEAN countries. However, these studies did not examine the impact of energy consumption on different expenditures in ASEAN countries, particularly on health and R\&D.

All these studies have although examined the association between energy consumption, environmental pollution, and economic growth $[21,32,33]$, they have hardly investigated the linkages between these variables with health and R\&D expenditures. Hence, a clear gap was identified in the existing literature with regard to the relationship between energy consumption, environmental pollution, and economic growth with R\&D and health expenditure in the context of ASEAN countries. This research gap rationalized the need for this current study.

\subsection{Environmental Pollution and Health Expenditure}

In all the past researches in terms of determinants, consequences, and different dimensions, an important perspective of environmental pollution that has been extensively researched is about its serious consequences on public health. In very recent research on organic as well as inorganic environmental pollution in developing countries and their impact on human health, Vaccari et al. [34] argued that pollutants spread via informal Waste Electrical and Electronic Equipment (WEEE) treatment services and could influence the human health adversely by exposure pathways or transportation process. As environmental pollution increases in a country, according to their findings, health conditions get adversely influenced due to which many health issues arise that must be controlled. Therefore, it is true that increasing environmental pollution always leads to increased health expenditure. However, this study, too, could not accumulate knowledge about the determinants of the increasing environmental pollution in health expenditure.

Jerrett et. al. [35], in exploratory research in Canada, argued that increased environmental pollution significantly increased the expenditure on health. They argued that the toxic pollution output was closely associated with per capita public environmental expenditure. Hence, countries with higher environmental pollution are likely to have higher per capita health expenditure as compared to countries with less environmental pollution. Since this research was limited to the Canadian perspective, the findings in ASEAN perspective might vary due to its varying health and environmental conditions. These countries also experience varying toxic diseases and health issues caused by contaminated and polluted air and, therefore, health expenditure, too, varies. A similar study by Chaabouni and Saidi [1] supported this argument. Based on a case study of 51 countries, the study suggested that with environmental pollution causing an impact on health, a unidirectional relationship exists between environmental pollution and expenditure on health. However, this research examined only two determinants of health spending, i.e., economic growth and environmental pollution, while other important predictors were ignored in this research.

The current argument was also supported by another research by Mehrara et. al. [36], who argued that there was a close association between health expenditure and quality of the environment. By using panel co-integration tests, error corrections models and Ordinary Least Square (OLS) to 
study the long-term equilibrium as well as short-term impact, the study found the evidence of a direct relationship between environmental quality and health expenditure in both short-run as well as long-run. Yazdi et. al. [37], in their research about Iran, too suggested that environmental quality and healthcare expenditure were closely associated. They also used Auto-Regressive Distributed Lag (ARDL) and co-integration approach to examine the long-term as well as short-term influences of environmental quality on health expenditure. Their argument was based on results showing that environmental pollution and different emissions had a positive impact on health expenditure. Narayan and Narayan [6] had also conducted research on OECD countries in which they argued that environmental quality (carbon emission) had a positive short-run impact on health expenditure. Similar results were reported by Assadzadeh et al. [38] in examining the link between carbon emission and health expenditures in eight oil-exporting nations. Another important research to be cited here is Zaidi and Saidi [17], who also argued that there was a two-way connection between environmental pollution and health expenditure.

All these studies have limited and regionally defined contexts, with no studies found in the context of ASEAN countries. Therefore, to explain this relationship in ASEAN perspective, the current study hypothesized that:

Hypothesis 1: "Environmental pollution has a significant positive impact on health expenditure of ASEAN countries."

\subsection{Environmental Pollution and RED Expenditure}

When environmental pollution increases, there are several concerns related to a country's environment and its natural resources. One of the concerns is the increase in the R\&D expenditure to control environmental issues and protect natural resources. Environmental pollution can also adversely affect natural resources and health conditions and, hence, there is a need to find innovative procedures to satisfy the growing needs of a country. It is argued that the problem of increasing environmental pollution can be addressed by focusing on $R \& D$ activities, which accounts for an increase in R\&D expenditure. Magnani [3] provided a similar argument in which it had been suggested that a country needs to increase its $R \& D$ expenditure for the sake of environmental protection. Based on data collected about public R\&D expenditure in OECD countries, the study found that, due to the inequality of income, a country is often unable to spend on environmental protection despite its willingness. However, it did not directly examine the impact of environmental pollution on the R\&D expenditure of OECD countries.

Likewise, it is also important to understand that a country needs to identify policies, methods, and the latest technologies to cope with several environmental issues caused by environmental pollution. This involves encouraging energy-efficient practices in both business and infrastructural layouts, for example, installation of lighting occupancy sensors that automatically turn lights on or off, depending on usage or occupancy. Moreover, a well-designed R\&D is crucially needed to conduct research and control the adverse impacts of environmental pollution in a country. For example, strategies should be directed to encourage research on eco-friendly technology across academic, technological, and industrial boundaries through providing finance for interdisciplinary and transdisciplinary research for high scientific quality and high environmental relevance that caters the aspects, such as knowledge of existing environmental needs, user preferences, regulations, control instruments, etc. in ASEAN perspective. Furthermore, considering the dominant role of Small and Medium Enterprises (SMEs) in the region, policies should also include SME to cooperate in and co-finance innovative projects of high environmental relevance by generating opportunities to boost renewal and innovation potentials of the people. Lee and Min [39] suggested that an increase in eco-friendly R\&D expenditures underlined the tendency to decline carbon emanations. Likewise, Apergis et al. [40] also signified the importance of R\&D investments in reducing carbon emanation in Europe. However, the relationship of carbon emission in enhancing technological change and augmented research and development 
is not recognized in the existing literature. Hence, there is a need to examine the relationship of environmental pollution represented by carbon emission to impact $R \& D$ expenditure in the particular perspective of the ASEAN region. Hence, the current study hypothesized that:

Hypothesis 2: "Environmental Pollution has a significant positive influence on RED expenditure of ASEAN countries."

\subsection{Energy Consumption and Health Expenditure}

As energy consumption in a country increases, it gives rise to several health issues resulting in the deterioration of the environment as a consequence of excessive energy consumption. The consumption of natural resources like coal, energy and gas, fossil fuels, etc. disturbs the environmental process, causing several health and environmental issues. To overcome these issues, and to avoid toxic effects of energy consumption on health in a country, there is a need to provide enough funds for health expenditure. It is, therefore, argued that higher energy consumption leads to higher public health expenditure. Arouri et al. [33], for instance, conducted research in the Middle East and North African countries to study the relationship between energy consumption, environmental pollution, and economic growth. They argued that energy consumption was closely related to environmental pollution because fossil fuel consumption and other natural resources' consumption adversely affect the environmental process and cause several health issues in the region. However, this research did not provide any empirical evidence of a direct impact of energy consumption on health expenditure. Another research study by Heidari et al. [32] also lacked this feature. They, however, examined the linkages among environmental pollution, economic growth, and energy consumption in ASEAN countries but did not provide any insights about the impact of these factors on health expenditure in any ASEAN country.

The current study argued that the higher is the energy consumption in a country, the greater is the expenditure on health, which is due to an increase in health issues and concerns associated with environmental pollution caused by energy consumption. Lean and Smyth [21] provided a supportive argument about the impact of energy consumption on $\mathrm{CO}_{2}$ emissions that consequently create several health issues. Another study by Saboori and Sulaiman [31] also provided strong insights about the linkage of $\mathrm{CO}_{2}$ emissions and energy consumption in ASEAN perspective. However, an in-depth literature review suggested that very scarce and limited studies about the direct impact of energy consumption on health expenditure exist. The current studies available on this association only considered energy consumption as a key predictor of environmental pollution but did not examine how energy consumption could increase a country's expenditure on health. A research gap is, therefore, clearly evident, leading to the third hypothesis of this study:

Hypothesis 3: "Energy consumption has a significant positive impact on health expenditure of ASEAN countries."

\subsection{Energy Consumption and RED Expenditure}

The fact that the increase in energy consumption in a country causes environmental pollution has been embraced by several past researchers, e.g., [5,21,31-33]. The environmental concerns raised due to environmental pollution require governments to find new ways, technology, policies, and procedures that can be incorporated to control environmental pollution and associated issues. For this purpose, proper research and development is needed to carry out appropriate studies on environmental pollution and find solutions to issues. It is, therefore, argued that the higher is the energy consumption, the greater will be the expenditure on R\&D of a country because $R \& D$ alone can address the problems and issues associated with environmental pollution factors, such as consumption of fossil fuels, coal, and other natural resources. Magnani [3], for instance, provided strong insights about countries that increased their $R \& D$ expenditure to protect their environment. This study collected R\&D expenditure 
data from OECD countries and argued as the income inequality countries have to face a gap between their ability to spend and willingness to spend on environmental protection. But the study did not examine the direct association between energy consumption and R\&D expenditure.

Another study by Bovenberg and Smulders [41] was also supportive of this argument as they also suggested the significance of having proper environmental policies to address environmental issues. An in-depth literature review further revealed a large scarcity of empirical evidence about a direct impact of energy consumption on R\&D expenditure. Particularly in the context of ASEAN countries too, there is no evidential research that might have examined a direct impact of energy consumption on R\&D expenditure.

The current study, therefore, was an attempt to contribute to this domain by showing how an increase in energy consumption raises environmental issues, necessitating an increase in a country's expenditure on R\&D to find a solution to those issues. The current study hence hypothesized that:

Hypothesis 4: "Energy consumption has a significant positive impact on RED expenditure of ASEAN countries."

\subsection{Economic Growth and Health Expenditure}

The economic growth of a nation is an important predictor of its human health, a determinant that has been extensively researched in previous studies. Economic growth may also be seen as a result of the enhanced expenditure on health. The higher is the economic growth of a country, the better are the conditions for the country, to spend on its health. Therefore, it is argued here that higher economic growth of country facilitates health expenditure; in other words, economic growth enhances the health expenditure of countries. Zaidi and Saidi [17] adopted the ARDL approach to study short-run as well as the long-run impact of economic growth on health expenditure in Sub-Saharan African countries. They found that the GDP of countries had a significant positive impact on health expenditure. However, this research was limited to Sub-Saharan African countries, and the evidence could not be applicable to the ASEAN perspective. Similarly, Chaabouni and Saidi [1] also supported this argument in their study on the relationship between economic growth and health expenditure. It was a case study of 51 countries, and its findings revealed that economic growth was an important predictor of health expenditure of the sampled countries, but they did not consider determinants of health expenditure, such as energy consumption taken up in the current study.

Another supporting study is by Lago-Peñas et. al. [42], who have examined the linkage of GDP with healthcare expenditure in 31 OECD countries. They suggested that healthcare expenditure could be potentially influenced by a change in per capita income. Since this research largely focused on income factor, such as GDP, other important elements were ignored. Truly, with the increase in per capita GDP of a country, health conditions to get enhanced because the country possesses enough capital and income to invest in the health sector and other domains for development. Wang [43] studied this relationship through two types of regression analysis: "panel regression analysis" and "quantile regression analysis" in the context of 31 countries. They found that when the growth of health expenditure was quantile, the impact of economic growth on expenditure also varied significantly. However, this research did not provide a clear understanding of the direct association of economic growth and health expenditure.

There are other past studies as well that examined the linkage between economic growth and health expenditure but with mixed findings, e.g., $[2,8,44,45]$. Though these studies unanimously agreed on the existence of a positive linkage between economic growth and health expenditure, none of them had any evidence about the ASEAN region. Therefore, the current study hypothesized that:

Hypothesis 5: "Economic growth has a significant positive influence on health expenditure of ASEAN countries." 


\subsection{Economic Growth and RED Expenditure}

The higher is the economic growth of a country, the better is its position to invest in its R\&D and introduce innovation in the country and to enhance its prosperity and growth. Alene [46] found evidence that increased R\&D expenditure led African agriculture to achieve enhanced productivity and growth; however, it did not examine the reverse association that economic growth increases the R\&D expenditure. Wang [47] studied determinants of R\&D investment in 26 OECD countries and suggested that economic growth was an important predictor of R\&D investment. Their research considered income growth rate a determinant of R\&D expenditure in the sampled OECD countries; however, its findings could not be generalized for the ASEAN countries. Bozkurt [9] also found a unidirectional relationship between economic growth and R\&D expenditure in Turkey but failed to provide any cross-country evidence.

An in-depth literature review hence suggested a lack of empirical studies on the influential role of economic growth in R\&D expenditure, particularly in the perspective of ASEAN countries; therefore, the current study hypothesized that:

Hypothesis 6: "Economic growth has a significant positive influence on RED expenditure of ASEAN countries."

\section{Methodology}

\subsection{Sample and Data}

This current study used annual data for ASEAN countries from 2009 to 2018 about the indicators of economic growth, environmental pollution, and energy consumption on health and R\&D expenditures of ASEAN nations. Purposive sampling method was used as it suited the requirements of the study. The data were collected to conduct empirical research on the ASEAN nations and to investigate the framed hypothesis around the chosen determinants of economic growth, environmental pollution, and energy consumption. The secondary data was collected for ten years period from the World Development Indicator managed by the World Bank. The "World Bank" website was given a priority owing to its authentic and relevant data content. All the variables were in absolute value; however, the data on health and R\&D expenditure were in the form of a percentage. The economic growth was measured in per capita of GDP, energy consumption was measured in per capita of $\mathrm{Kg}$ of oil equivalent, and environmental pollution was measured in per capita of metric tons. Moreover, health and R\&D expenditure were measured in \% of GDP.

\subsection{Definition and Measurement of Variables}

The data was collected by selecting proper proxies for each variable. The current paper included five key variables: two dependent and three independent variables.

\subsubsection{Dependent Variables}

Two separate econometric models were developed to analyze the short-term as well as the long-term impact of the dependent variables. These two dependent variables were "health expenditure" and "R\&D expenditure". The measurement of health expenditure was performed by adding up all the public and private health expenditure of the ASEAN countries. The R\&D expenditure was, however, calculated by summing up the R\&D budgeted spending of the ASEAN countries.

\subsubsection{Independent Variables}

Three independent variables were been examined as predictors of health expenditure and $R \& D$ expenditure in short-run as well as long-run. These variables were environmental pollution, energy consumption, and economic growth. The environmental pollution was measured using $\mathrm{CO}_{2}$ emissions, 
while energy use per capita was calculated as a proxy to measure energy consumption. The economic growth was measured using GDP growth.

\subsection{Modeling and Methodological Framework}

To meet the objectives of this study of examining the association between environmental pollution, energy consumption, and economic growth, and health and R\&D expenditures of ASEAN countries for which data for past ten years (2009 to 2018) was collected, this study analyzed short-term as well as long-term effect of independent variables on dependent variables. The ARDL approach was used to complete the modeling of the data collected and the variables. A similar approach was used by Zaidi and Saidi [17] to investigate the short-term and long-term linkage of $\mathrm{CO}_{2}$ emissions, GDP, and health expenditure.

\subsubsection{ARDL Approach}

ARDL is an "Autoregressive Distributed Lag" approach, which is usually employed to analyze short-term and long-term relationships between variables for a given period. The ARDL approach has certain advantages: it can help evoke intra as well as inter dimensions of a model. Furthermore, it has asymptotic properties that can be helpful in the estimation of independent variables of stationary as well as non-stationary series. In the current paper, the Pooled Mean Group (PMG) method was used, which is crucially a version of ARDL approach. This method was used to estimate the ARDL model with the likelihood at a maximum level. The ARDL model can also be rephrased as an "error correction model" (ECM) because it tends to induce simultaneously the inter as well as intra dimensions. The PMG estimator was originally developed by Pesaran et al. [48] and is associated with the category of dynamic panel modeling.

While following this modeling in the current study, a number of observations were assumed to be as large as the number of individuals. It means that the number of " $\mathrm{T}$ " was considered to be as large as that of " $\mathrm{N}$ ". According to PMG estimators, the long-run coefficients were constrained to be matching to ECM because, in PMG estimate, the long-run coefficients were likely to vary from the error variances. This estimator was followed by undertaking the assumptions that the short-term coefficient is heterogeneous, while long-run slope coefficients are homogenous [49]. The initial conditions in this estimating method were considered as random or fixed, while the long-run coefficients were considered as a non-linear amalgamation of short-run coefficients.

The ARDL, i.e., "Autoregressive Distributed Lag" modeling has been efficiently used and enhanced by past researchers to assess the long-run and short-run associations of variables, e.g., [17]. ARDL models for the current study, including the long-run association between variables, are as follow:

$$
\begin{aligned}
& \Delta H E_{i t}=\alpha_{i}+\sum_{j=\mathbf{1}}^{m-1} \beta_{i j} \Delta H E_{i, t-j}+\sum_{l=\mathbf{0}}^{n-1} \varphi_{i l} \Delta C O_{2 i, t-l}+\sum_{r=0}^{p-1} \mathbf{Y}_{i r} \Delta E C_{i, t-r}+ \\
& \sum_{u=0}^{s-1} \theta_{i u} \Delta G D P_{i, t-u}+\delta_{1} H E_{i . t-1}+\delta_{2} C O_{2 i . t-1}+\delta_{3} E C_{i . t-1}+\delta_{4} G D P_{i . t-1}+\varepsilon_{1 i, t} \\
& \Delta R D_{i t}=\alpha_{i}+\sum_{j=\mathbf{1}}^{m-1} \beta_{i j} \Delta R D_{i, t-j}+\sum_{l=0}^{n-1} \varphi_{i l} \Delta C O_{2 i, t-l}+\sum_{r=0}^{p-1} \mathbf{Y}_{i r} \Delta E C_{i, t-r}+ \\
& \sum_{u=\mathbf{0}}^{s-1} \theta_{i u} \Delta G D P_{i, t-u}+\pi_{1} R D_{i . t-1}+\pi_{2} C O_{2 i . t-1}+\pi_{3} E C_{i . t-1}+\pi_{4} G D P_{i . t-1}+\varepsilon_{2 i, t},
\end{aligned}
$$

where HE is the health expenditure and the dependent variable in the first model; RD is the research and development expenditure and the dependent variable in the second model; $\boldsymbol{\alpha}_{i}$ denotes constant, which is country-specific intercept; $\mathrm{CO}_{2}$ is the $\mathrm{CO}_{2}$ emission, which was measured with proxy as a metric ton per capita; 'EC' stands for energy consumption, which was measured with energy use per capita in a year; 'GDP' represents the economic growth, which was measured with GDP growth; and finally $\varepsilon_{k i, t}$ is the error term in which $(k=1,2)$. These are the first variance operators.

In the very first step of ARDL modeling, the optimal lag length was decided for each variable of the study. For this purpose, the minimization of "Schwarz information criterion" (SBIC) was used for a grid 
search. At this step, the null hypotheses are formulated about no co-integration between the current variables. The null hypotheses for Equations (1) and (2) were formulated as follows, respectively:

$$
\begin{gathered}
H_{0}: \delta_{1}+\delta_{2}+\delta_{3}+\delta_{4}=0 \\
H_{0}: \pi_{1}+\pi_{2}+\pi_{3}+\pi_{4}=0
\end{gathered}
$$

The alternative hypotheses against these null hypotheses suggested that co-integration was not equal to zero. When the values of "Fisher statistics" were larger than zero, the null hypotheses were rejected.

The second step of the ARDL approach proceeded after the decision about null hypotheses of co-integration had been taken. If the null hypotheses of the co-integration were not rejected, then the long-term relationship between the variables could be estimated. The long-term relationship of the current ARDL model for Equations (1) and (2) could be written as follows, respectively:

$$
\begin{aligned}
& H E_{i t}=\mu_{i}+\sum_{j=1}^{m-1} \lambda_{1 j} H E_{i, t-j}+\sum_{l=0}^{n-1} \lambda_{\mathbf{2}} C O_{2 i, t-l}+\sum_{r=0}^{p-1} \lambda_{3 j} E C_{i, t-r}+\sum_{u=0}^{s-1} \lambda_{4 j} G D P_{i, t-u}+v_{1 i, t}, \\
& R D_{i t}=\mu_{i}+\sum_{j=1}^{m-1} \lambda_{1 j} R D_{i, t-j}+\sum_{l=0}^{n-1} \lambda_{2 j} C O_{2 i, t-l}+\sum_{r=0}^{p-1} \lambda_{3 j} E C_{i, t-r}+\sum_{u=0}^{s-1} \lambda_{4 j} G D P_{i, t-u}+v_{2 i, t}
\end{aligned}
$$

The assumptions of the PMG approach had also been considered while developing these equations about the long-term relationship of variables since the coefficients of long-term relationships remained the same for each country. At this step, the assumption specific to co-integration null hypothesis had also been respected for above-mentioned ARDL models. After developing long-run relationships for both ARDL models of the current study, the "error correction terms" were determined from these relationships. These "error correction models" would be used to estimate the short-term relationships between variables:

$$
\begin{aligned}
& \Delta H E_{i t}=\alpha_{i}+\sum_{j=1}^{m-1} \beta_{i j} \Delta H E_{i, t-j}+\sum_{l=0}^{n-1} \varphi_{i l} \Delta C O_{2 i, t-l}+\sum_{r=0}^{p-1} Y_{i r} \Delta E C_{i, t-r}+ \\
& \sum_{u=0}^{s-1} \theta_{i u} \Delta G D P_{i, t-u}+a E C T_{t-1}+\mathrm{e}_{1 i, t} \\
& \Delta R D_{i t}=\boldsymbol{\alpha}_{i}+\sum_{j=1}^{m-1} \beta_{i j} \Delta R D_{i, t-j}+\sum_{l=0}^{n-1} \varphi_{i l} \Delta C O_{2 i, t-l}+\sum_{r=0}^{p-1} \Upsilon_{i r} \Delta E C_{i, t-r}+ \\
& \sum_{u=0}^{s-1} \theta_{i u} \Delta G D P_{i, t-u}+b E C T_{t-1}+\mathrm{e}_{2 i, t},
\end{aligned}
$$

where the $\mathrm{e}_{k i, t}$ is the residual $(k=1,2)$ and $E C T_{t-1}$ is the "error correction term", which is defined through the "long-run equilibrium relationship" between variables. The parameters $(a, b)$ used in these models indicated the speed of alteration to the equilibrium level. These parameters were estimated by using "nonlinear algorithm" of "Newton-Raphson" following the method of Pesaran et al. [48]. The estimators found that the results of this method were normally consistent and concurrently distributed. The "pooling" and "averaging" were also involved in these intermediate estimators. According to PMG approach, the short-run dynamic conditions were allowed that were different for different countries; however, long-run coefficients were the same for all countries. This approach had certain advantages in comparison to "Dynamic OLS" and "fully modified OLS" methods.

The last step of the ARDL approach was "Granger causality tests" that were performed in three ways by following [40]. At this stage, the short-run connections were assessed by considering: " $H_{0}: \varphi_{i l}=0$ " for all " $i$ " and $l \geq 1$ in Equations (5) and (6). Then, the long-run connections were tested in all these equations from the Error Correction Term (ECT). The null hypotheses in this causality test in Equations (5) and (6) was " $H_{0}: a=0, H_{0}: b=0$ ", respectively. Finally, the strong causalities in both models were tested. For instance, the null hypothesis for checking strong causality from $\mathrm{CO}_{2}$ emission to HE was " $\varphi_{i l}=a=0$ " for all " $i$ " and $l \geq 1$. Similarly, the null hypothesis for Equation (6) was also specified. 


\subsubsection{Panel Unit Root Test}

Before performing econometric modeling, there was a need to analyze the stationarity of the data sets as it was required for econometric analysis. The panel unit root test becomes more important when research involves macroeconomic or financial data because it is needed to define the order of integration before applying any co-integration technique on this data. It was necessary to ensure the stationarity of variables to avoid any problems related to fallacious regression in case if the variables were not stationary. Normally, the panel unit root test involves Augmented Dickey Fuller (ADF) Fisher Chi-square (ADF Fisher) and Levin, Lin, and Chi (LLC) unit root tests" for macroeconomic data. Hence, these tests were selected for the current study.

\section{Empirical Findings}

For the current study, the data from 2009 to 2018 were collected from different secondary sources with ASEAN countries as a sample in this study. Some initial but important tests were applied to check the normality and suitability of the data for major analysis. For instance, descriptive statistics were used to assess the descriptive features of data for ensuring its normality and adequacy. It was ensured that there was no outlier in the data of any variable, and data were normally distributed and appropriate for which its mean value, minimum and maximum statistics, standard deviation as well as skewness statistics were some key indicators used and interpreted. The skewness statistics is a very good indicator of normality of data and should fall within the range of -1 to +1 .

Table 1 depicts the overall acceptability and normality of data of both variables. Outcomes showed that data were normal for each variable because every construct had a skewness value under the threshold range from -1 to +1 . Moreover, other values like mean, minimum, and maximum statistics showed that the current data had no outliers.

Table 1. Descriptive Statistics.

\begin{tabular}{cccccc}
\hline Test & RD & HE & GDP & EC & CO $_{2}$ \\
\hline Mean & 0.883800 & 3.939443 & 5.283240 & 2205.206 & 4.547337 \\
Median & 0.740587 & 3.675714 & 5.973367 & 958.9194 & 1.612607 \\
Maximum & 2.159960 & 7.583306 & 15.24038 & 9829.333 & 24.60718 \\
Minimum & 0.055300 & 1.686957 & -2.465515 & 251.3355 & 0.152848 \\
Std. Dev. & 0.693801 & 1.490673 & 2.898637 & 2579.883 & 6.220351 \\
Skewness & 0.587140 & 0.571528 & -0.480000 & 0.638023 & 0.914250 \\
Kurtosis & 2.075627 & 2.495882 & 4.395097 & 2.588205 & 2.945612 \\
Jarque-Bera & 9.305827 & 6.502969 & 11.94956 & 55.22864 & 97.22520 \\
Probability & 0.009534 & 0.038717 & 0.002542 & 0.000000 & 0.000000 \\
Sum & 88.38002 & 393.9443 & 528.3240 & 220520.6 & 454.7337 \\
Sum Sq. Dev. & 47.65466 & 219.9885 & 831.8078 & 659.08 & 3830.584 \\
Observations & 100 & 100 & 100 & 100 & 100 \\
\hline
\end{tabular}

Note: $\mathrm{RD}=$ Research and development expenditure, $\mathrm{HE}=$ Health Expenditure, GDP = Gross domestic products proxy for economic growth, $\mathrm{EC}=$ energy consumption, $\mathrm{CO}_{2}=$ Environmental pollution.

\subsection{Correlation Test}

The correlation test was used to examine whether there was an association between variables of study or not and what type of association was present between them. The most commonly used test for the assessment of the correlation between variables is the Pearson correlation test.

The correlation of each variable was obvious from the results given in Table 2. For instance, the correlation of RD with itself was one, that of HE with itself was one, that of GDP with itself was also one, that of EC, as well as the last correlation of $\mathrm{CO}_{2}$ with itself, was also one. It means that the discriminant validity of current data was ensured because a variable must correlate with itself more than within any other variable. The table includes the correlation value along with the P-value and $\mathrm{t}$-statistics against this correlation value to suggest the significance of these results. The acceptable 
correlation value for a positive correlation is normally $>0.3$, and its P-value must be less than 0.05 . The significance of results further required the $t$-statistics to be more than $t$-tabulated. The correlation value between RD, HE, GDP, EC, and CO2 were significant current results having $\mathrm{t}$-value greater than $\mathrm{t}$-tab and P-value less than 0.05 .

Table 2. Correlation Results.

\begin{tabular}{|c|c|c|c|c|c|}
\hline \multicolumn{6}{|c|}{ t-Statistic } \\
\hline Probability & RD & HE & GDP & EC & $\mathrm{CO}_{2}$ \\
\hline $\mathrm{RD}$ & $\begin{array}{c}.000000 \\
----- \\
-----\end{array}$ & & & & \\
\hline $\mathrm{HE}$ & $\begin{array}{c}-0.534096 \\
-6.254006 \\
0.000000\end{array}$ & $\begin{array}{c}1.000000 \\
----- \\
-----\end{array}$ & & & \\
\hline GDP & $\begin{array}{c}-0.380210 \\
-4.069502 \\
0.0001\end{array}$ & $\begin{array}{c}0.162642 \\
1.631800 \\
0.1059\end{array}$ & $\begin{array}{c}1.000000 \\
---- \\
----\end{array}$ & & \\
\hline $\mathrm{EC}$ & $\begin{array}{l}0.816955 \\
14.02362 \\
0.000000\end{array}$ & $\begin{array}{c}-0.459086 \\
-5.115673 \\
0.000000\end{array}$ & $\begin{array}{c}-0.591313 \\
-7.258670 \\
0.000000\end{array}$ & $\begin{array}{c}1.000000 \\
---- \\
-----\end{array}$ & \\
\hline $\mathrm{CO}_{2}$ & $\begin{array}{l}0.747435 \\
11.13778 \\
0.000000\end{array}$ & $\begin{array}{c}-0.411492 \\
-4.469499 \\
0.000000\end{array}$ & $\begin{array}{c}-0.646100 \\
-8.380006 \\
0.000000\end{array}$ & $\begin{array}{l}0.948801 \\
29.73539 \\
0.000000\end{array}$ & $\begin{array}{c}1.000000 \\
----- \\
----\end{array}$ \\
\hline
\end{tabular}

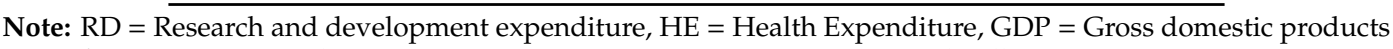
proxy for economic growth, $\mathrm{EC}=$ energy consumption, $\mathrm{CO}_{2}=$ Environmental pollution.

\subsection{Assumptions of ARDL Approach}

Before applying the ARDL approach to the data, there were some assumptions necessary to prove their satisfactory level, as follows:

\subsubsection{Data Stationarity}

It is a prerequisite and assumption of the ARDL approach that the data for each construct should be stationary at the level or first difference I (1). However, the ARDL model allows that if some constructs have stationarity at the level and some have at the 1st difference, it is acceptable. So, stationarity of the data at I (2) is not acceptable in the ARDL approach. For this purpose, ADF Fisher Chi-square (ADF Fisher) and Levin, Lin, and Chi (LLC) were applied to check the stationarity of the data. Before applying unit root tests, the joint graph of all constructs, indicating the trend of each variable, was created (Figure 2).

The graph present that most variables have their trend at stationarity level; however, to confirm this stationarity, the unit root analysis was applied. Table 3 present the results of the unit root test.

As seen in the graph, most variables were stationary at level; the results of ADF and LLC test also indicated that all variables are stationary at 1st difference, fulfilling the condition of the ARDL approach. However, results also showed that some variables were stationary at the level as well, like RD and GDP in the ADF test, while RD, EC, and CO2 were stationary in LLC test. 


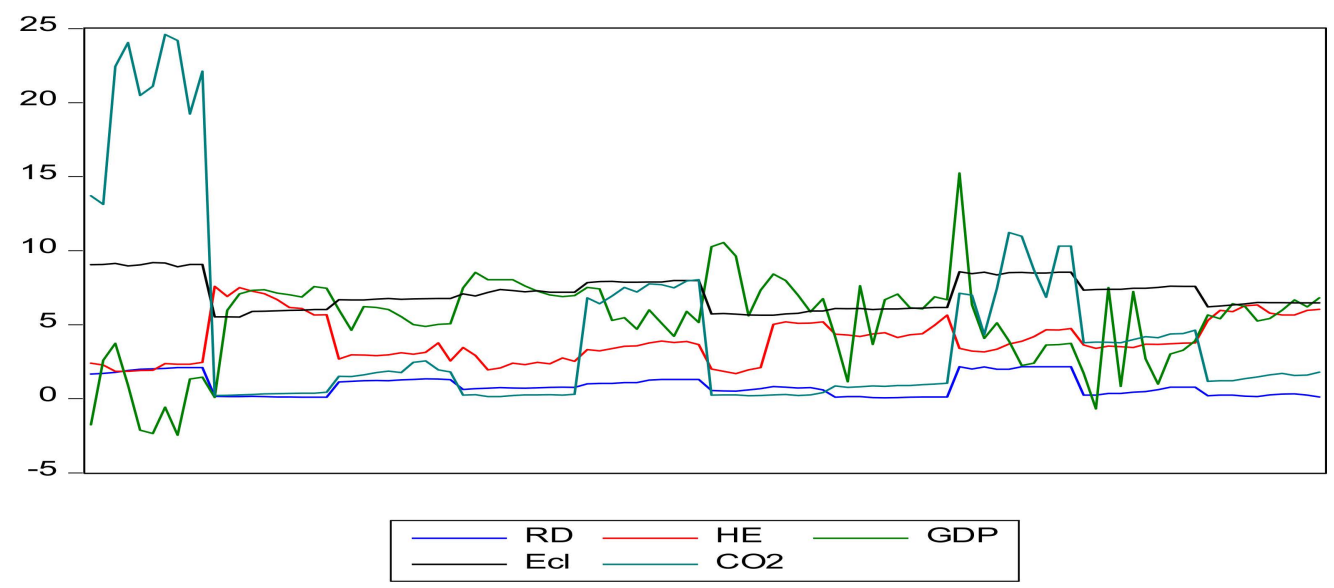

Figure 2. Joint Trends.

Table 3. Unit Root Analysis.

\begin{tabular}{ccccc}
\hline \multirow{2}{*}{ Constructs } & \multicolumn{2}{c}{ ADF Test } & \multicolumn{2}{c}{ LLC Test } \\
\cline { 2 - 5 } & At Level & 1st Difference & At Level & 1st Difference \\
\hline $\mathrm{HE}$ & 17.0336 & $73.6361^{* * *}$ & $-0.62877^{* *}$ & $-4.23906^{* * *}$ \\
$\mathrm{RD}$ & $28.5654^{*}$ & $25.8970^{*}$ & $-4.30799^{* * *}$ & $-3.98399^{* * *}$ \\
$\mathrm{EC}$ & $26.5808^{*}$ & $33.3896^{*}$ & $-3.71221^{* *}$ & $-4.21096^{* * *}$ \\
$\mathrm{GDP}$ & $36.5799^{*}$ & $47.2471^{* * *}$ & $-0.65915^{*}$ & $-2.07879^{*}$ \\
$\mathrm{CO}_{2}$ & 22.0843 & $53.2398^{* * *}$ & $-2.09090^{*}$ & $-8.97472^{* * *}$ \\
\hline
\end{tabular}

Note: $\mathrm{RD}=$ Research and development expenditure, $\mathrm{HE}=$ Health Expenditure, GDP = Gross domestic products proxy for economic growth, $\mathrm{EC}=$ energy consumption, $\mathrm{CO}_{2}=$ Environmental pollution, $\mathrm{LLC}=$ Levin, Lin, and Chi. $*, * *, * * *$ denoted as significance at level $5 \%, 1 \%$, and $0.1 \%$, respectively.

\subsubsection{Heteroscedasticity Test}

The second assumption of the ARDL approach is that data must be free from the problem of heteroscedasticity, which is a problem of pattern in data distribution [50]. The researchers checked it in both models by applying heteroscedasticity test (Table 4). There are two hypotheses regarding the heteroscedasticity test:

$\mathrm{H}_{0}$ : Heteroscedasticity exists in the model.

$\mathrm{H}_{1}$ : Heteroscedasticity does not exist in the model.

Heteroscedasticity tests for both models proved that there was no issue of heteroscedasticity in the data, fulfilling the 2nd assumption of ARDL approach.

Table 4. Heteroscedasticity Test.

\begin{tabular}{ccccc}
\hline Dependent Variable & S. Value & DF & Probability & Null Hypothesis \\
\hline HE & 5.316656 & 10 & 0.8690 & Rejected \\
RD & 1.9834780 & 10 & 0.9965 & Rejected \\
\hline
\end{tabular}

\subsubsection{Co-Integration Test}

If the residuals of variable and stationarity of the constructs need to be co-integrated, by using Eviews 10, a cointegration test is to be applied. Null hypothesis indicates an absence of cointegration, while the alternative hypothesis states the existence of cointegration [51]. The findings of the cointegration test in this study are shown in Table 5. 
Table 5. Co-Integration Analysis.

\begin{tabular}{ccccc}
\hline \multicolumn{5}{c}{ Alternative Hypothesis: Common AR Coefficients (within-dimension) } \\
Weighted \\
\hline & Statistic & Prob. & Statistic & Prob. \\
\hline Panel v-Statistic & $-2.447929 *$ & 0.0262 & 21.336387 & 0.0193 \\
Panel rho-Statistic & $2.730734^{*}$ & 0.0968 & 2.634982 & 0.0458 \\
Panel PP-Statistic & $-3.793224^{* * *}$ & 0.0001 & -4.120508 & 0.0000 \\
Panel ADF-Statistic & 0.192145 & 0.5762 & -0.474465 & 0.3176 \\
\hline Alternative Hypothesis: Individual AR Coefficients (between-dimension) \\
\hline \multicolumn{5}{c}{ Prob. } \\
\hline Group rho-Statistic & 4.067592 & 0.00001 & \\
Group PP-Statistic & -7.113317 & 0.0000 & \\
Group ADF-Statistic & -0.122626 & 0.4512 & \\
\hline Kao test. & Statistic & Prob. & \\
\hline ADF & $-1.604157^{*}$ & 0.0457 & \\
\hline
\end{tabular}

Note: ${ }^{*}{ }^{* *}, * *$ denoted as significance at level $5 \%, 1 \%$, and $0.1 \%$, respectively.

The outcomes in Table 5 showed that all statistics were significantly co-integrated, except penal $\mathrm{ADF}$ and group ADF. The rest all were significant and rejected the null hypothesis. Moreover, Kao test proved the significance of the ADF test until we were in the position to run the ARDL approach to investigate the long- and short-term relationship for health and R\&D expenditures.

\subsection{ARDL Results}

In the current study, a PMG method was used with the ARDL approach. This method assumes the presence of cointegration. This method was applied when asymptotic properties were required for explanatory variables that are either stationary or not, but it helps to obtain the long and short-term relationship in an econometric model [51]. Table 6 presents the outcomes of the ARDL approach for both models.

Table 6. ARDL Results.

\begin{tabular}{|c|c|c|c|}
\hline \multirow{3}{*}{$\begin{array}{l}\text { Dependent } \\
\text { Variables }\end{array}$} & \multicolumn{3}{|c|}{ Independent Variables } \\
\hline & \multicolumn{3}{|c|}{ Long-Run Estimations } \\
\hline & $\mathrm{CO}_{2}$ & EC & GDP \\
\hline $\mathrm{HE}$ & $\begin{array}{c}0.517269^{* * *} \\
(5.0312)\end{array}$ & $\begin{array}{c}-0.008960 \text { *** } \\
(-5.2468)\end{array}$ & $\begin{array}{c}0.521607^{* * *} \\
\quad(6.6752)\end{array}$ \\
\hline $\mathrm{RD}$ & $\begin{array}{c}0.029525 * * * \\
(35.9975)\end{array}$ & $\begin{array}{c}0.584505^{* * *} \\
(68.8935)\end{array}$ & $\begin{array}{c}0.017151^{* * *} \\
(71.663)\end{array}$ \\
\hline \multicolumn{4}{|c|}{ Short-run estimations } \\
\hline $\mathrm{HE}$ & $\begin{array}{l}0.810250 \\
(-0.6815)\end{array}$ & $\begin{array}{c}0.003219 \\
(0.7871)\end{array}$ & $\begin{array}{c}0.020190 \\
(0.2150)\end{array}$ \\
\hline $\mathrm{RD}$ & $\begin{array}{c}-0.189422 \text { * } \\
(-2.0871)\end{array}$ & $\begin{array}{l}0.854505 \\
(0.3334)\end{array}$ & $\begin{array}{l}0.006630 * \\
(2.08651)\end{array}$ \\
\hline
\end{tabular}

Note: $\mathrm{RD}=$ Research and development expenditure, $\mathrm{HE}=$ Health Expenditure, GDP $=$ Gross domestic products proxy for economic growth, $\mathrm{EC}=$ energy consumption, $\mathrm{CO}_{2}=$ Environmental pollution, $\mathrm{ARDL}=$ Auto-Regressive Distributed Lag. ${ }^{*}, * * * * *$ denoted as significance at level $5 \%, 1 \%$, and $0.1 \%$, respectively.

Results of the ARDL approach (Table 6) indicated that environmental pollution had a positive and significant impact on health expenditure in the long-term estimation, whereas, its impact in short-term estimations was insignificant. The results of energy consumption indicated that it had a positive and significant impact on health and R\&D expenditures in the long-run, but in short-term, it had an 
insignificant impact on both dependent variables. The findings also revealed that economic growth had a positive and significant impact in long-run estimations on health and R\&D estimations, whereas it had a significant effect on R\&D in short-term but insignificant on health expenditure.

\subsection{Granger Causality}

In the current study, "Wald statistics" was used to perform the causality tests because the commonly used t-statistics and F-statistics were less flexible and, therefore, could not be used. At the first step in this test, the long-term causalities were tested for the current variables as given in Table 7. It can be seen in Table 7 that long-term causality running from $\mathrm{CO}_{2}$ emissions, energy consumption, and GDP growth to health expenditure was significant. Similarly, the long-term causality running from GDP growth, $\mathrm{EC}$, and $\mathrm{CO}_{2}$ emission was also significant.

Table 7. Long-term Causality Statistics.

\begin{tabular}{ccccc}
\hline \multirow{2}{*}{ Dependent Variable } & \multicolumn{4}{c}{ Statistics } \\
\cline { 2 - 5 } & Wald & P-Value & Fisher & P-Value \\
\hline HE & $10.982603^{* * *}$ & 0.0001 & $10.982603^{* * * *}$ & 0.0001 \\
RD & $13.952201^{* * *}$ & 0.0001 & $13.952201^{* * *}$ & 0.0001 \\
\hline
\end{tabular}

Note: ${ }^{* * *}$ indicates the significance of results at a $1 \%$ level.

After estimating the long-term causality of models, the strong causalities were tested. The results of strong causalities are presented in Table 8.

Table 8. Strong Causality Statistics.

\begin{tabular}{ccccc}
\hline Causality Direction & Wald & P-Value & Fisher & P-Value \\
\hline $\mathrm{GDP} \rightarrow \mathrm{HE}$ & $12.45736^{* * *}$ & 0.0001 & $9.582995^{* * * *}$ & 0.0001 \\
$\mathrm{EC} \rightarrow \mathrm{HE}$ & $18.52950^{* * *}$ & 0.0001 & $12.05992^{* * *}$ & 0.0001 \\
$\mathrm{CO} 2 \rightarrow \mathrm{HE}$ & $14.70421^{* * *}$ & 0.0001 & $11.04992^{* * *}$ & 0.0001 \\
$\mathrm{EC}, \mathrm{GDP}, \mathrm{CO}_{2} \rightarrow \mathrm{HE}$ & $24.74134^{* *}$ & 0.0210 & $18.04985^{* *}$ & 0.0210 \\
$\mathrm{HE} \rightarrow \mathrm{CO} \mathrm{CO}_{2}$ & 2.96324 & 0.20521 & 1.425665 & 0.21213 \\
$\mathrm{HE} \rightarrow \mathrm{GDP}$ & 4.01242 & 0.2104 & 2.146677 & 0.31084 \\
$\mathrm{HE} \rightarrow \mathrm{EC}$ & 2.00421 & 0.15960 & 1.685986 & 0.35900 \\
$\mathrm{GDP} \rightarrow \mathrm{RD}$ & $17.48556^{* *}$ & 0.03259 & $12.69495^{* *}$ & 0.03829 \\
$\mathrm{EC} \rightarrow \mathrm{RD}$ & $12.48050^{* * *}$ & 0.0001 & $5.63114^{* * *}$ & 0.0001 \\
$\mathrm{CO} \rightarrow \mathrm{RD}$ & $9.04892^{* * *}$ & 0.0001 & $5.156674^{* * *}$ & 0.0001 \\
$\mathrm{GDP}, \mathrm{EC}, \mathrm{CO} 2 \rightarrow \mathrm{RD}$ & $29.05829^{* * *}$ & 0.0001 & $20.96869^{* * *}$ & 0.0001 \\
$\mathrm{RD} \rightarrow \mathrm{CO} 2$ & 2.89521 & 0.2109 & 1.0596949 & 0.35109 \\
$\mathrm{RD} \rightarrow \mathrm{GDP}$ & 1.48590 & 0.1953 & 1.00002 & 0.2953 \\
$\mathrm{RD} \rightarrow \mathrm{EC}$ & 2.05949 & 0.59285 & 1.05568 & 0.50985 \\
\hline
\end{tabular}

Note: ${ }^{* * *}$ indicates the significance of results at a $1 \%$ level, while ${ }^{* *}$ indicates the significance of values at a $5 \%$ level.

It can be seen in Table 8 that strong causality running from either $\mathrm{EC}, \mathrm{CO}_{2}$, or GDP to HE was significant. However, the inverse causal paths from health expenditure to any of the independent variable (i.e., $\mathrm{EC}, \mathrm{CO}_{2}$, or GDP) were not significant. It means that results provided great evidence about strong causalities running from $\mathrm{EC}, \mathrm{CO}_{2}$, and GDP to $\mathrm{HE}$, but there was no significant causality reported by results running from $\mathrm{HE}$ to any of $\mathrm{CO}_{2}, \mathrm{GDP}$, or EC. Similarly, results revealed that there was no strong causality running from $\mathrm{R} \& \mathrm{D}$ expenditure to $\mathrm{CO}_{2}$, GDP, or $\mathrm{EC}$; however, there was strong causality running from $\mathrm{CO}_{2}, \mathrm{GDP}$, and $\mathrm{EC}$ (energy consumption) to R\&D expenditure. It means that there were no significant inverse causalities between current variables.

Finally, the short-terms causality test was completed to assess the short-run connections between variables. The results of short-term causality are presented in Table 9. It was found that short-term causality running from EC, $\mathrm{CO}_{2}$, and GDP to health expenditure was not significant. Moreover, there 
was no inverse causality running from health expenditure to any of the independent variables, i.e., EC, $\mathrm{CO}_{2}$, and GDP.

Table 9. Short-term Causality Statistics.

\begin{tabular}{ccccc}
\hline Causality Direction & Wald & P-Value & Fisher & P-Value \\
\hline $\mathrm{GDP} \rightarrow \mathrm{HE}$ & 2.154506 & 0.0941 & 2.05406 & 0.0962 \\
$\mathrm{EC} \rightarrow \mathrm{HE}$ & 8.04550 & 0.20184 & 6.04550 & 0.22185 \\
$\mathrm{CO}_{2} \rightarrow \mathrm{HE}$ & 8.04221 & 0.2959 & 5.04221 & 0.30013 \\
$\mathrm{EC}, \mathrm{GDP}, \mathrm{CO}_{2} \rightarrow \mathrm{HE}$ & 2.14134 & 0.6821 & 2.00034 & 0.8520 \\
$\mathrm{HE} \rightarrow \mathrm{CO} 2$ & 4.90324 & 0.2089 & 1.90324 & 0.2189 \\
$\mathrm{HE} \rightarrow \mathrm{GDP}$ & 2.14242 & 0.0831 & 1.80042 & 0.12831 \\
$\mathrm{HE} \rightarrow \mathrm{EC}$ & 1.91422 & 0.15059 & 1.077910 & 0.16059 \\
$\mathrm{GDP} \rightarrow \mathrm{RD}$ & $17.48556 * *$ & 0.0201 & 11.04547 ** & 0.03301 \\
$\mathrm{EC} \rightarrow \mathrm{RD}$ & 8.28358 & 0.25885 & 3.97288 & 0.35885 \\
$\mathrm{CO}{ }_{2} \rightarrow \mathrm{RD}$ & $12.41065 * * *$ & 0.0001 & $8.91000 * * *$ & 0.0001 \\
$\mathrm{GDP}, \mathrm{EC}, \mathrm{CO} \rightarrow \mathrm{RD}$ & 6.04991 & 0.0919 & 2.00011 & 0.1919 \\
$\mathrm{RD} \rightarrow \mathrm{CO} 2$ & 4.59290 & 0.25929 & 2.192994 & 0.3329 \\
$\mathrm{RD} \rightarrow \mathrm{GDP}$ & 2.68288 & 0.15883 & 1.80018 & 0.26783 \\
$\mathrm{RD} \rightarrow \mathrm{EC}$ & 3.08592 & 0.48593 & 1.89001 & 0.50985 \\
\hline
\end{tabular}

Note: ${ }^{* *}$ indicates the significance of results at a $1 \%$ level, while ${ }^{* *}$ indicates the significance of values at a $5 \%$ level.

It can be seen in Table 9 that no short-term causality was proved either from $\mathrm{HE}$ to $\mathrm{EC}, \mathrm{CO}_{2}$, and GDP, or from EC, $\mathrm{CO}_{2}$, and GDP to HE. It means that there was no significant causality of $\mathrm{CO}_{2}, \mathrm{EC}$, and GDP to health expenditure. Furthermore, it was found through results that causality running from $\mathrm{CO}_{2}$ and GDP to R\&D expenditure was significant; however, the causality running from EC to $\mathrm{R} \& \mathrm{D}$ was not significant. Moreover, there was no significant causality running from either $\mathrm{CO}_{2}$, GDP, or EC to R\&D expenditure. Hence, it could be concluded through "Granger causality test" that there was no inverse significant path in the current study.

\section{Discussion of Results}

The current study examined the linkage between economic growth, energy consumption, environmental pollution, and expenditure on health and R\&D in the context of ASEAN countries by using ARDL approach. The empirical results were found by checking short-run as well as the long-run association of independent and dependent variables. In response to the first hypothesis of the current study, i.e., "Environmental pollution has a significant positive impact on health expenditure", the empirical results of ASEAN countries revealed that environmental pollution had a significant positive influence on health expenditure in the long-run; however, there was no significant association of environmental pollution with health expenditure in short-run. It was also found that the health expenditure was derived by environmental pollution in long-run not in short-run, so the first hypothesis of the current study was accepted from a long-term perspective. These results were in line with past studies, e.g., $[1,2,17,34,37]$. All these researchers have reported positive linkage between environmental pollution and health expenditure, suggesting that the current results are in line with past findings.

In response to the second hypothesis of the current study, i.e., "Environmental Pollution has a significant positive influence on R\&D expenditure", the current results revealed that there was a significant positive association between environmental pollution and R\&D in long-run as well as short-run because the increasing environmental pollution immediately causes the health and other issues for which R\&D needs to be mobilized quickly. Therefore, a short-term and long-term positive impact was reported by $\mathrm{CO} 2$ emissions on R\&D expenditure. Hence, this hypothesis was accepted through the current results. The existing supportive studies and findings in the literature are insufficient to support these current findings of the direct impact of environmental pollution on R\&D expenditure because there is a lack of literature about this relationship. However, the arguments of Bovenberg and 
Smulders [41] and Magnani [3] can be referred here to support the current relationship and findings because they suggest some indirect linkage between environmental pollution and R\&D expenditure.

The next two hypotheses of the current research paper were about the impact of energy consumption on health expenditure and R\&D expenditure. In response to the third and fourth hypotheses, it was found that the energy consumption had significant impacts on health as well as R\&D expenditure in long-run; however, the impacts of energy consumption on health and R\&D expenditure in short-run were insignificant. It means that the impacts of energy consumption on R\&D and health expenditure were not immediately realized; rather, the energy consumption took time to influence the expenditure on R\&D and health. Hence, the third and fourth hypotheses of the current study were true from a long-run perspective. These results about the significant impact of energy consumption on health expenditure could be supported by past studies of Arouri et al. [33], Heidari et al. [32], Lean and Smyth [21], and Saboori and Sulaiman [31] because they argued that energy consumption gives rise to environmental pollution, ultimately enhancing the health expenditure of countries. It means that the long-run impact of energy consumption on health expenditure can be supported through these past studies. The long-term impact of energy consumption on R\&D expenditure found in the current study was insufficiently supported through past studies due to the lack of literature about the direct relationship between energy consumption and R\&D expenditure.

In response to the last two hypotheses about the impact of economic growth on health and $R \& D$ expenditure, it was found that the economic growth had a significant positive influence on health expenditure in long-run, but there was no significant impact of economic growth on health expenditure in short-run. Similarly, it was found that the economic growth had a significant impact on R\&D expenditure in short-run as well as long-run, so fifth and sixth hypotheses of the current paper were also accepted through current findings. These results were in line with several past studies, e.g., $[2,9,17,28,31-33,43,45]$. All these studies somehow argued the positive association of economic growth with health expenditure and R\&D expenditure of countries. Hence, all current results were in line with past findings.

\section{Conclusions}

The current study examined the linkage of economic growth, environmental pollution, energy consumption, health expenditure, and R\&D expenditure for which the data were collected for the past ten years for ASEAN countries. It was found through results that all hypotheses of the current study were true. These results suggested that environmental pollution did not increase the health expenditure in short-run because it takes time to realize the impact of environmental pollution on health expenditure. The impact of environmental pollution on R\&D expenditure was also found through current results. Furthermore, it was found that economic growth had a short-term and long-term impact on R\&D expenditure, while the impact of economic growth on health expenditure was only realized in long-run. The impact of energy consumption on health as well as R\&D expenditure was only realized in long-run, while there was no impact of energy consumption on R\&D and health expenditure in short-run.

The current study would have a great contribution in theory and practice because, theoretically, it would enhance the existing literature through important empirical findings of ASEAN countries, so the existing gap in the literature about association of environmental pollution, economic growth, energy consumption, health expenditure, and R\&D expenditure regarding ASEAN countries would be fulfilled. Practically, this research would assist ASEAN countries in determining the role of environmental pollution, economic growth, and energy consumption in determining their health and R\&D expenditure. Eventually, they would be able to frame policies accordingly. There were also some limitations of the current study that should be overcome in future researches. The current study examined only unidirectional connections between variables, while there exist bi-directional relationships between current variables as well. So, researchers are directed to examine these bi-directional relationships. Furthermore, researchers should also conduct research on other regions as well because the current 
findings were limited to the ASEAN region. Moreover, the study could be further extended by adding the variable related to monetary policy, fiscal policy, and any government regulated variables, such as political stability, corruption, interest rate, etc.

Author Contributions: The following was the contribution of each author of this study. M.H. has worked on the original idea. M.H. has performed the detailed conceptualization and investigation of this research. H.I.H. has finalized the methodology. H.I.H. has conducted data analysis of this research. S.K. has performed the write up of this project including the writing of original draft. S.K. has performed the data collection and data analysis. M.H. has written the final draft and done the review, proof reading and editing for final submission. K.J. has coordinated the methodology and data analysis stage of this research project.

Funding: This research received no external funding.

Conflicts of Interest: The authors declare no conflict of interest.

\section{References}

1. Chaabouni, S.; Saidi, K. The dynamic links between carbon dioxide $\left(\mathrm{CO}_{2}\right)$ emissions, health spending and GDP growth: A case study for 51 countries. Environ. Res. 2017, 158, 137-144. [CrossRef] [PubMed]

2. Chaabouni, S.; Zghidi, N.; Mbarek, M.B. On the causal dynamics between $\mathrm{CO}_{2}$ emissions, health expenditures and economic growth. Sustain. Cities Soc. 2016, 22, 184-191. [CrossRef]

3. Magnani, E. The Environmental Kuznets Curve, environmental protection policy and income distribution. Ecol. Econ. 2000, 32, 431-443. [CrossRef]

4. Sagarik, D. Determinants of health expenditures in ASEAN region: Theory and evidence. Millenn. Asia 2016, 7, 1-19. [CrossRef]

5. Fang, Y. Economic welfare impacts from renewable energy consumption: The China experience. Renew. Sustain. Energy Rev. 2011, 15, 5120-5128. [CrossRef]

6. Narayan, P.K.; Narayan, S. Does environmental quality influence health expenditures? Empirical evidence from a panel of selected OECD countries. Ecol. Econ. 2008, 65, 367-374. [CrossRef]

7. Ke, X.; Saksena, P.; Holly, A. The Determinants of Health Expenditure: A Country-level Panel Data Analysis; World Health Organization: Geneva, Switzerland, 2011; Volume 26.

8. Behera, D.; Dash, U. Nexus between public health expenditure and income: Empirical evidence from Indian states. Nexus 2016, 11, 44.

9. Bozkurt, C. R\&D expenditures and economic growth relationship in Turkey. Int. J. Econ. Financ. Issues 2015, 5, 188-198.

10. Damijan, J.P.; Knell, M.; Majcen, B.; Rojec, M. The role of FDI, R\&D accumulation and trade in transferring technology to transition countries: Evidence from firm panel data for eight transition countries. Econ. Syst. 2003, 27, 189-204.

11. Di Matteo, L. The macro determinants of health expenditure in the United States and Canada: Assessing the impact of income, age distribution and time. Health Policy 2005, 71, 23-42. [CrossRef]

12. Li, Y.; Wu, Q.; Xu, L.; Legge, D.; Hao, Y.; Gao, L.; Wan, G. Factors affecting catastrophic health expenditure and impoverishment from medical expenses in China: Policy implications of universal health insurance. Bull. World Health Organ. 2012, 90, 664-671. [CrossRef] [PubMed]

13. Hollanders, D.; Koster, F. The Graying of the Median Voter: Aging and the Politics of the Welfare State in OECD Countries; Amsterdam Institute for Advanced labour Studies, University of Amsterdam: Amsterdam, The Netherlands, 2010.

14. Garrone, P.; Grilli, L. Is there a relationship between public expenditures in energy R\&D and carbon emissions per GDP? An empirical investigation. Energy Policy 2010, 38, 5600-5613.

15. Kahouli, B. The causality link between energy electricity consumption, $\mathrm{CO}_{2}$ emissions, R\&D stocks and economic growth in Mediterranean countries (MCs). Energy 2018, 145, 388-399.

16. Apergis, N.; Gupta, R.; Lau, C.K.M.; Mukherjee, Z. US state-level carbon dioxide emissions: Does it affect health care expenditure? Renew. Sustain. Energy Rev. 2018, 91, 521-530. [CrossRef]

17. Zaidi, S.; Saidi, K. Environmental pollution, health expenditure and economic growth in the Sub-Saharan Africa countries: Panel ARDL approach. Sustain. Cities Soc. 2018, 41, 833-840. [CrossRef]

18. Watts, N.; Adger, W.N.; Agnolucci, P.; Blackstock, J.; Byass, P.; Cai, W.; Cox, P.M. Health and climate change: Policy responses to protect public health. Lancet 2015, 386, 1861-1914. [CrossRef] 
19. McMichael, A.J. Globalization, climate change, and human health. N. Engl. J. Med. 2013, 368, $1335-1343$. [CrossRef]

20. Kan, H.; Chen, R.; Tong, S. Ambient air pollution, climate change, and population health in China. Environ. Int. 2012, 42, 10-19. [CrossRef]

21. Lean, H.H.; Smyth, R. $\mathrm{CO}_{2}$ emissions, electricity consumption and output in ASEAN. Appl. Energy 2010, 87, 1858-1864. [CrossRef]

22. Wang, Z.; Asghar, M.M.; Zaidi, S.A.H.; Wang, B. Dynamic linkages among $\mathrm{CO}_{2}$ emissions, health expenditures, and economic growth: Empirical evidence from Pakistan. Environ. Sci. Pollut. Res. 2019, 26, 15285-15299. [CrossRef]

23. Zhixia, C.; Hossen, M.M.; Muzafary, S.S.; Begum, M. Green Banking for Environmental Sustainability-Present Status and Future Agenda: Experience from Bangladesh. Asian Econ. Financ. Rev. 2018, 8, 571-585. [CrossRef]

24. Koçak, E.; Ulucak, Z.Ş. The effect of energy R\&D expenditures on $\mathrm{CO}_{2}$ emission reduction: Estimation of the STIRPAT model for OECD countries. Environ. Sci. Pollut. Res. 2019, 26, 14328-14338.

25. Capstick, S.; Whitmarsh, L.; Poortinga, W.; Pidgeon, N.; Upham, P. International trends in public perceptions of climate change over the past quarter century. Wiley Interdiscip. Rev. Clim. Chang. 2015, 6, 35-61. [CrossRef]

26. Salim, R.A.; Islam, N. Exploring the impact of R\&D and climate change on agricultural productivity growth: The case of Western Australia. Aust. J. Agric. Resour. Econ. 2010, 54, 561-582.

27. Baioumy, N.; Ismail, M.Z.; Ab Rahman, R.; Mohd, T.; Annuar, M.Z.M.; Haridi, E.A. The Effectiveness of a Proposed Strategy Based on Video Stories on Youtube in the Development of Listening and Speaking Skills among the Non-Arabic Speakers. Int. J. Acad. Res. Bus. Soc. Sci. 2018, 8. [CrossRef]

28. Ismail, A.G. Electricity Consumption and Economic Growth in ASEAN Countries; Universiti Teknologi MARA: Selagnor, Malaysia, 2016.

29. Hill, M.K. Understanding Environmental Pollution; Cambridge University Press: Cambridge, UK, 2010.

30. Lan, J.; Kakinaka, M.; Huang, X. Foreign direct investment, human capital and environmental pollution in China. Environ. Resour. Econ. 2012, 51, 255-275. [CrossRef]

31. Saboori, B.; Sulaiman, J. $\mathrm{CO}_{2}$ emissions, energy consumption and economic growth in Association of Southeast Asian Nations (ASEAN) countries: A cointegration approach. Energy 2013, 55, 813-822. [CrossRef]

32. Heidari, H.; Katircioğlu, S.T.; Saeidpour, L. Economic growth, $\mathrm{CO}_{2}$ emissions, and energy consumption in the five ASEAN countries. Int. J. Electr. Power Energy Syst. 2015, 64, 785-791. [CrossRef]

33. Arouri, M.E.H.; Youssef, A.B.; M'henni, H.; Rault, C. Energy consumption, economic growth and $\mathrm{CO}_{2}$ emissions in Middle East and North African countries. Energy Policy 2012, 45, 342-349. [CrossRef]

34. Vaccari, M.; Vinti, G.; Cesaro, A.; Belgiorno, V.; Salhofer, S.; Dias, M.I.; Jandric, A. WEEE Treatment in Developing Countries: Environmental Pollution and Health Consequences-An Overview. Int. J. Environ. Res. Public Health 2019, 16, 1595. [CrossRef]

35. Jerrett, M.; Eyles, J.; Dufournaud, C.; Birch, S. Environmental influences on healthcare expenditures: An exploratory analysis from Ontario, Canada. J. Epidemiol. Community Health 2003, 57, 334-338. [CrossRef] [PubMed]

36. Mehrara, M.; Sharzei, G.; Mohaghegh, M. The Relationship between Health Expenditure and Environmental Quality in Developing Countries. J. Health Adm. 2011, 14, 79-88.

37. Yazdi, S.K.; Zahra, T.; Nikos, M. Public Healthcare Expenditure and Environmental Quality in Iran. In Recent Advances in Applied Economics. 2014. Available online: http://www.wseas.us/e-library/conferences/2014/ Lisbon/AEBD/AEBD-17.pdf (accessed on 12 January 2018).

38. Assadzadeh, A.; Bastan, F.; Shahverdi, A. The impact of environmental quality and pollution on health expenditures: A case study of petroleum exporting countries. In Proceedings of the 29th International Business Research Conference, Sydney, Australia, 24-25 November 2014; pp. 24-25.

39. Lee, K.H.; Min, B. Green R\&D for eco-innovation and its impact on carbon emissions and firm performance. J. Clean. Prod. 2015, 108, 534-542.

40. Apergis, N.; Eleftheriou, S.; Payne, J.E. The relationship between international financial reporting standards, carbon emissions, and R\&D expenditures: Evidence from European manufacturing firms. Ecol. Econ. 2013, $88,57-66$.

41. Bovenberg, A.L.; Smulders, S. Environmental quality and pollution-augmenting technological change in a two-sector endogenous growth model. J. Public Econ. 1995, 57, 369-391. [CrossRef] 
42. Lago-Peñas, S.; Cantarero-Prieto, D.; Blázquez-Fernández, C. On the relationship between GDP and health care expenditure: A new look. Econ. Model. 2013, 32, 124-129. [CrossRef]

43. Wang, K.-M. Health care expenditure and economic growth: Quantile panel-type analysis. Econ. Model. 2011, 28, 1536-1549. [CrossRef]

44. Behera, D.K.; Dash, U. Impact of GDP and tax revenue on health care financing: An empirical investigation from Indian states. Theor. Appl. Econ. 2017, 2, 249-266.

45. Gövdeli, T. Health Expenditure, Economic Growth, and $\mathrm{CO}_{2}$ Emissions: Evidence from the OECD Countries. Adıyaman Üniversitesi Sos. Bilimler Enstitüsü Derg. 2019, 31, 488-516.

46. Alene, A.D. Productivity growth and the effects of R\&D in African agriculture. Agric. Econ. 2010, 41, $223-238$.

47. Wang, E.C. Determinants of R\&D investment: The Extreme-Bounds-Analysis approach applied to 26 OECD countries. Res. Policy 2010, 39, 103-116.

48. Pesaran, M.H.; Shin, Y.; Smith, R.P. Pooled mean group estimation of dynamic heterogeneous panels. J. Am. Stat. Assoc. 1999, 94, 621-634. [CrossRef]

49. Asongu, S.; El Montasser, G.; Toumi, H. Testing the relationships between energy consumption, CO 2 emissions, and economic growth in 24 African countries: A panel ARDL approach. Environ. Sci. Pollut. Res. 2016, 23, 6563-6573. [CrossRef] [PubMed]

50. Sun, C.; Zhang, F.; Xu, M. Investigation of pollution haven hypothesis for China: An ARDL approach with breakpoint unit root tests. J. Clean. Prod. 2017, 161, 153-164. [CrossRef]

51. Murthy, V.N.; Okunade, A.A. Determinants of US health expenditure: Evidence from autoregressive distributed lag (ARDL) approach to cointegration. Econ. Model. 2016, 59, 67-73. [CrossRef]

(C) 2019 by the authors. Licensee MDPI, Basel, Switzerland. This article is an open access article distributed under the terms and conditions of the Creative Commons Attribution (CC BY) license (http://creativecommons.org/licenses/by/4.0/). 